\title{
DÜBLIN
}

Technological University Dublin ARROW@TU Dublin

2003-01-01

\section{Broadband Dual-plate Monopole Antennas}

Z. Wu

University of Manchester

P. Sevret

University of Manchester

Max Ammann

Technological University Dublin, max.ammann@tudublin.ie

Follow this and additional works at: https://arrow.tudublin.ie/engschececon

\section{Recommended Citation}

Wu, Z., Sevret, P., \& Ammann, M. (2003) Broadband dual-plate monopole antennas. ICAP 2003, Twelfth International Conference on Antennas and Propagation, University of Exeter, U.K. (Conf. Publ. No. 491), Vol.2, pp493-495. 31 March-3 April, 2003, doi:10.1049/cp:20030120

This Conference Paper is brought to you for free and open access by the School of Electrical and Electronic Engineering at ARROW@TU Dublin. It has been accepted for inclusion in Conference papers by an authorized administrator of ARROW@TU Dublin. For more information, please contact arrow.admin@tudublin.ie, aisling.coyne@tudublin.ie, gerard.connolly@tudublin.ie.

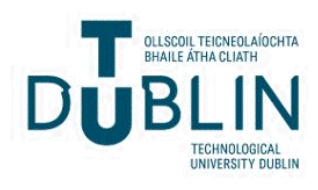




\title{
BROADBAND DUAL-PLATE MONOPOLE ANTENNAS
}

\author{
$\mathrm{Z} \mathrm{Wu}{ }^{*}, \mathrm{P}$ Sevret ${ }^{*}$ and $\mathrm{M} \mathrm{J}$ Ammann ${ }^{* *}$ \\ *: Department of Electrical Engineering and Electronics, UMIST, Manchester, M60 1QD, UK \\ **: School of Electronic and Communications Engineering, Dublin Institute of Technology, Ireland.
}

\section{INTRODUCTION}

Planar monopole antennas employing square and other geometries have been demonstrated to have large impedance bandwidth [1-8]. A square monopole has a typical impedance bandwidth ratio (IBR) of 1:2.4 [2]. The ratio can be improved by employing a short circuit at an edge of the planar monopole [4]. A typical value of 1:4 may be achieved [2]. The introduction of short circuit also reduces the lower end matching frequency (LEMF). Significant improvement in bandwidth can also be achieved by trimming the square monopole plate, which results in an increase in the higher end matching frequency (HEMF). It has been shown by Ammann [5] that the LEMF is determined by the length of the square plate. At this frequency the length of the plate is approximately $1 / 5$ of the wavelength. This is relatively large. It is therefore necessary to reduce the LEMF so as to improve the bandwidth at the lower end of the frequency or reduce the antenna size for a given LEMF. Dual-plate monopole antennas are thus proposed in this paper to improve the impedance performance. The investigation of the dual plate antennas and variations are described below. The experimental results of return loss of these antennas are compared with those of single plate monopoles. The radiation patterns of a dual plate antenna at various frequencies are also presented.

\section{SINGLE- AND DUAL- PLATE MONOPLE ANTENNAS}

The structures of the single- and dual- plate monopole antennas on a ground plane of $15 \mathrm{~cm} \times 15 \mathrm{~cm}$ used for experimental studies are shown in Table 1 . They include single-plate and dual plate monopole antennas without and with short circuits and/or edge trimming. Each antenna is assigned a code, with $\mathrm{S}$ in the first letter denoting single plate, $S$ in the second letter indicating a short- circuited edge, $\mathrm{D}$ denoting dual-plate, and $\mathrm{T}$ indicating edge trimming. For comparison, the dimensions of the plates are kept the same, i.e. $25 \mathrm{~mm} \mathrm{x}$ $25 \mathrm{~mm}$, for all single- and dual- plate antennas. The length of the feed probe may change slightly between antennas as it is chosen for an 'optimal' performance for each antenna.

\section{EXPERIMENTAL RESULTS}

Figure 1 shows the measured return loss response of the single plate antenna " $S$ ". The frequency range of $10 \mathrm{~dB}$ return loss is from $2.26 \mathrm{GHz}$ to $5.23 \mathrm{GHz}$, giving an IBR of 1:2.3. The return loss response of the shorted single plate antenna "SS" is also shown in Fig.1 for comparison. By shorting the plate at the edge, the LEMG is reduced to $1.86 \mathrm{GHz}$, but the HEMF is almost unchanged. By trimming the lower edges of the plate with $\alpha=30^{\circ}$, the HEMF can be increased beyond $20 \mathrm{GHz}$, as shown in Fig. 2 for antenna "ST". The use of a shorting pin at the edge can again reduce the LEMF. The return loss of the antenna "SST" is also shown in Fig.2.

Figure 3 shows the measured return loss response of the dual-plate antenna " $D$ ". The frequency range of $10 \mathrm{~dB}$ return loss is from $2.14 \mathrm{GHz}$ to $4.04 \mathrm{GHz}$, giving an IBR of $1: 1.9$. The bandwidth is smaller than the single plate antenna " $\mathrm{S}$ ", but the LEMF is slightly lower. The LEMF can be further reduced by introducing a shorting pin at one of the edges, creating the structure of antenna "DS". The return loss of antenna "DS" is compared in Fig.3. The LEMF of the "DS" antenna is $1.55 \mathrm{GHz}$. In comparison with single plate antennas, the LEMF of the shorted dual-plate antenna is lowered by $17 \%$. But the HEMF is also lowered, by $14 \%$. By trimming the lower edges of the plates with $\alpha=45^{\circ}$, the HEMF can be increased beyond $20 \mathrm{GHz}$, as shown in Fig.4 for antenna "DT". The use of a shorting pin at the edge again reduces the LEMF, as shown in Fig.4 for antenna "DST". The HEMF is however also lowered.

Both the single plate and the dual-plate types of antennas have frequency-dependent radiation patterns over the $10 \mathrm{~dB}$ return loss bandwidth. The measured radiation patterns of the "DT" antenna at various frequencies are shown in Fig.5. The antenna radiates like a wire monopole at lower frequencies. However, the patterns, particularly the E-plane patterns, change significantly at higher frequencies.

\section{DISCUSSION AND CONCLUSIONS}

In this paper, dual-plate monopole antennas without and with a shorting pin and/or edge trimming have been studied. The experimental results of return loss 
have been presented, and compared with single plate monopole antennas. It has been shown that the lower end matching frequency can be lowered by $17 \%$ by using dual plates. The higher end matching frequency can be improved by edge trimming. Despite of their frequency-dependent radiation patterns, these planar monopoles with a BWR of $1: 7$ or above can serve as a wideband antenna for a range of portable wireless terminals.

\section{REFERENCES}

[1] Ammann M.J., "The Pentagonal Planar Monopole For Digital Mobile Terminals; Bandwidth Consideration and Modelling", IEE International Conference on Antennas and Propagation, Manchester, 2001, 82-85. [2] Ammann M.J., Doyle L.E., "Small Planar Monopole covers Multiband BRANs", $30^{\text {th }}$ European Microwave Conference, Paris, 2000, 242-246.
[3] Chen Z.N., 2000: "Impedance Characteristics of Planar Bow-tie-like Monopole Antennas", Electronics Letters, 36(13), 120-122.

[4] Lee E., Hall P.S., Gardner P., "Compact Wideband Planar Monopole Antenna", Electronics letters, 1999, 35(25), 2157-2158.

[5] Ammann M.J., 1999: "Square Planar Monopole Antenna", IEE National Conference on Antennas and Propagation, York, 37-40.

[6] Agrawall N. P., Kumar G., Ray K.P., "Wide-Band Planar Monopole Antennas", IEEE Transactions on Antennas and Propagation, 1998, 46 (2), 294-295.

[7] Honda S., Ito M., Seki H., Jinbo Y., "A Disk Monopole Antenna with 1:8 Impedance Bandwidth and Omnidirectional Radiation Pattern", Proc. ISAP, 1992, Sapporo, Japan, 1145-1148.

[8] Dubost G., "Flat Radiating Dipoles and Applications to arrays", Research Studies Press, John Wiley \& Sons, 1981.

Table 1: Structures and impedance bandwidth

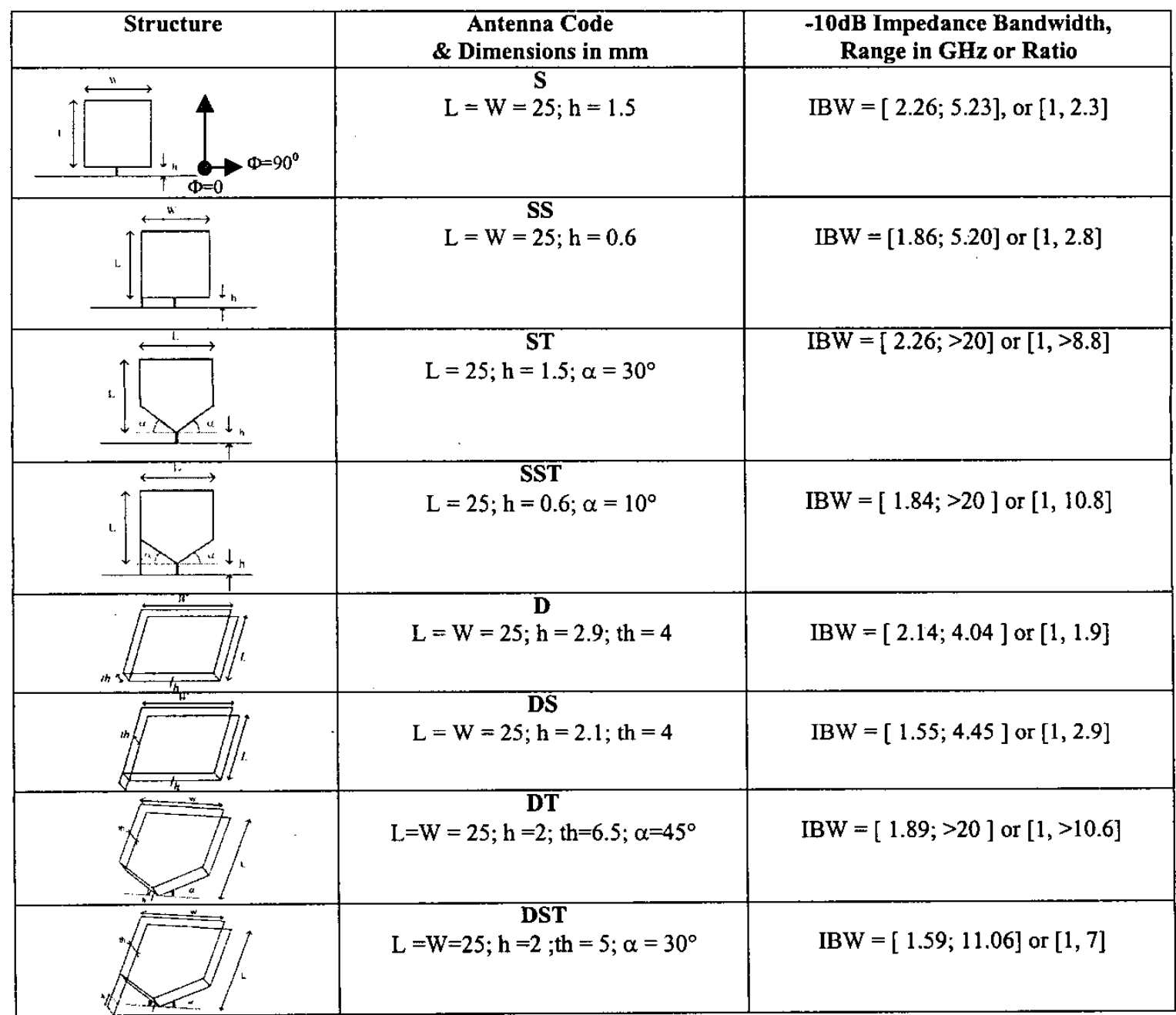


S11

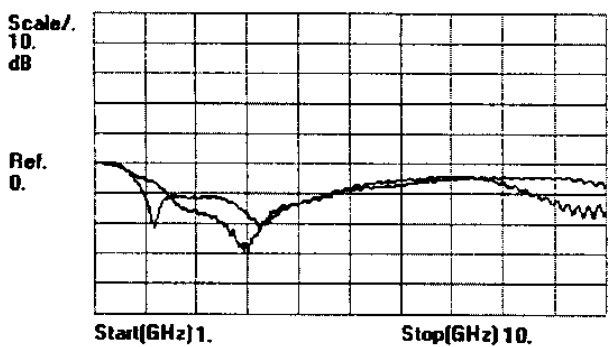

Fig.1 Return loss of antennas "S" and "SS"

\$11

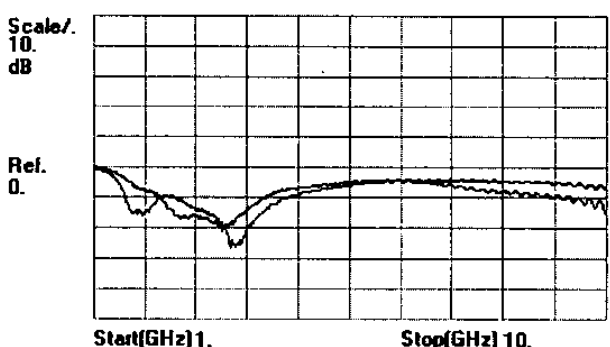

Fig.3 Return loss of antennas "D" and "DS"

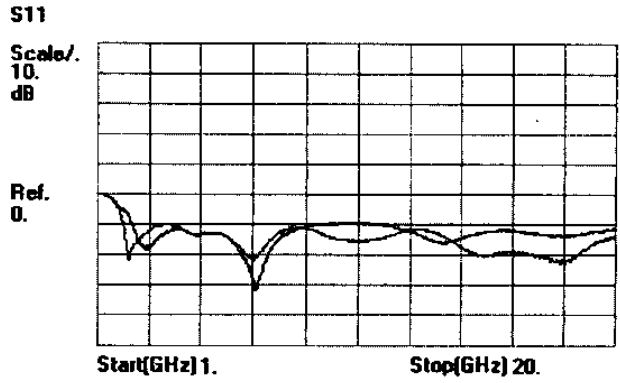

Fig.2 Return loss of antennas "ST" and "SST"

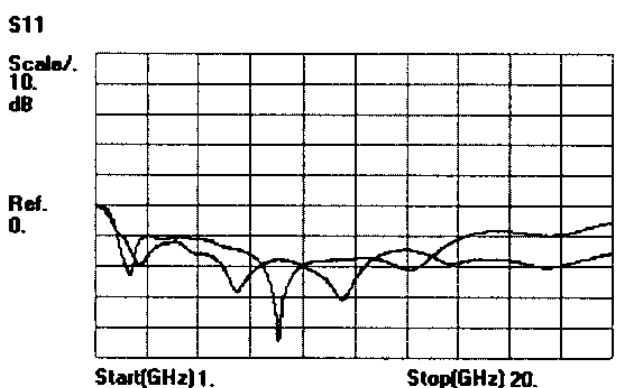

Fig.4 Return loss of antennas "DT" and "DST"
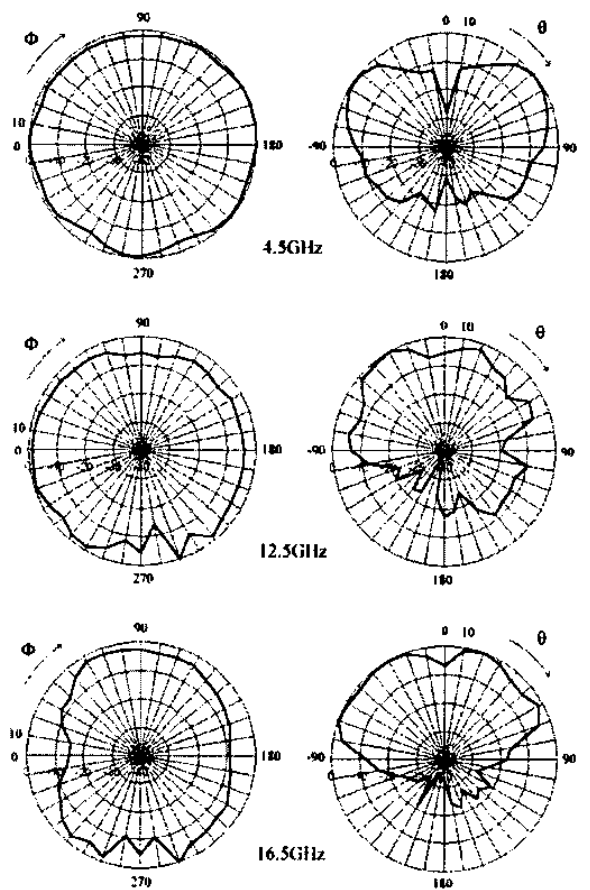

Fig.5 H-plane $\left(\theta=90^{\circ}, \Phi\right)$ patterns (left) and E-plane $\left(\theta, \Phi=0^{\circ}\right)$ patterns (right) of the "DT" antenna at various frequencies. 